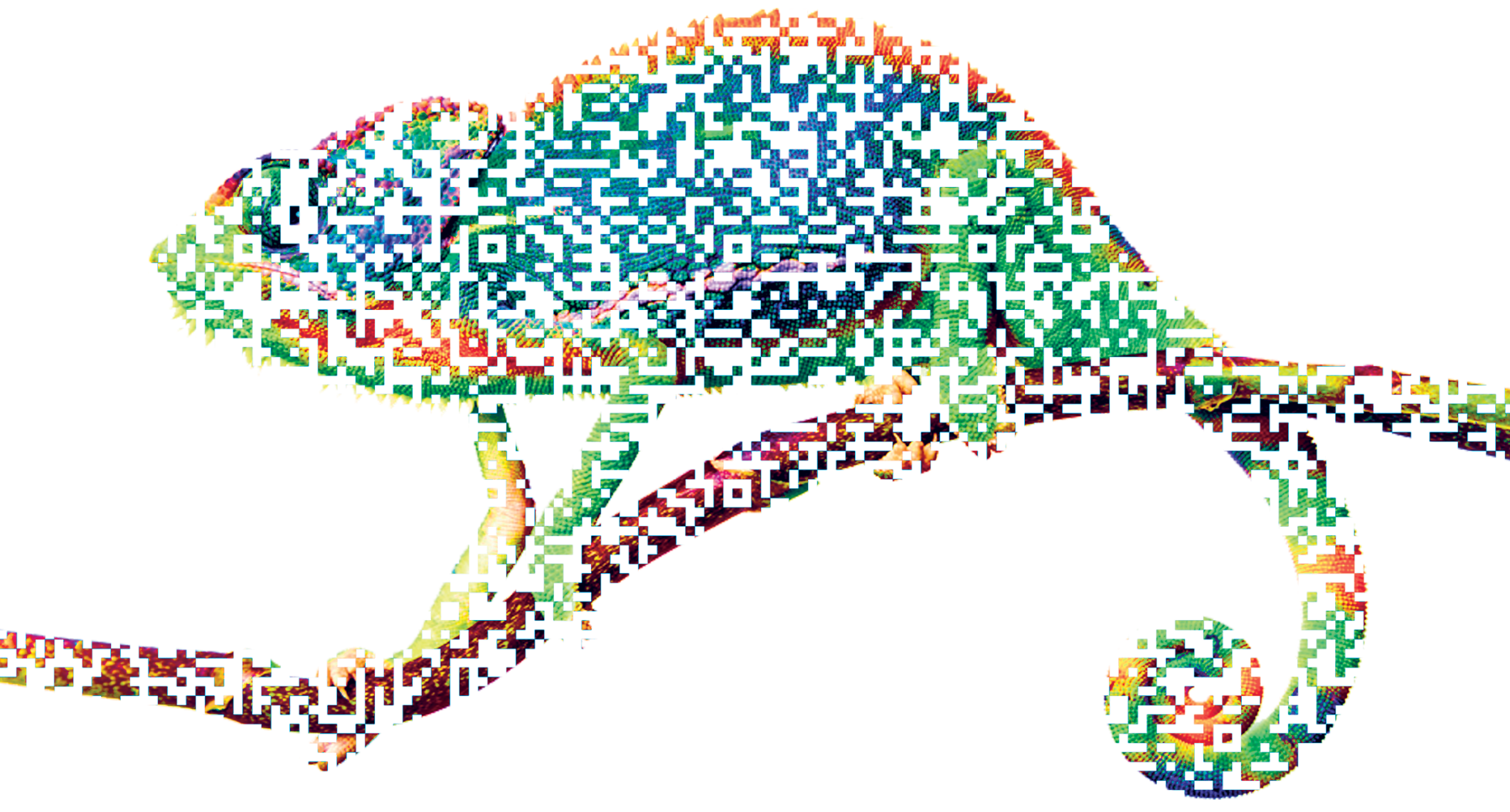


Nuevos códigos

para la enseñanza

del color.

Adoptando

el lenguaje

del Processing

Fernanda Márquez Suárez 


\section{Nuevos códigos para la enseñanza del color. Adoptando el lenguaje de Processing}

\section{Fernanda Márquez Suárez}

Licenciada en Diseño Gráfico. Docente en Centro de Diseño, Cine y Televisión.

fmarquez@centro.edu.mx

Fecha de recepción: 13 de enero, 2017

Fecha de aceptación: 24 de enero, 2017

\section{Resumen}

El trabajo describe una experiencia de adopción de código digital para la enseñanza de color a nivel universitario mediante Processing. Se explican el contexto, el enfoque y los resultados preliminares alcanzados por tres grupos de control de programas creativos (diseño, arquitectura de interiores, entre otras). Se evidencia la problemática relacionada con la adquisición de este nuevo lenguaje, que impacta tanto profesores como a alumnos. Entre otros resultados de interés, se observó un contraste significativo entre las expectativas generales cifradas por los alumnos en este recurso, versus las aplicaciones prácticas que identifican a nivel personal; asimismo, se observó una asimilación diferenciada de acuerdo con la carrera que cursaba cada participante al momento del estudio.

Palabras clave | color; código; Processing; diseño; análogo; digital 
NUEVOS CÓDIGOS PARA LA ENSEÑANZA DEL COLOR. ADOPTANDO EL LENGUAJE DEL PROCESSING

\begin{abstract}
This work describes an experience of adoption of Digital Code for the color teaching at university-level. Explains the context, the approach and the preliminary results achieved by three control groups of creative programs (Design, Interior Design, among others). Shows the problems related to the acquisition of this new language, impacting both teachers and students. Among other interesting results, there was a significant contrast between the general expectations by students about this resource, versus the practical applications that they identify in a personal level; it was also observed a differentiated assimiliation according to the career.
\end{abstract}

Keywords | color; code; Processing; design; analog; digital 
NUEVOS CÓDIGOS PARA LA ENSEÑANZA DEL COLOR.

\section{Introducción}

Este trabajo aborda una experiencia de adopción del lenguaje digital para la enseñanza de color en Centro de Diseño, Cine y Televisión (CENTRO), institución educativa mexicana dedicada a la profesionalización de la creatividad.

Históricamente, la enseñanza de color en CENTRO se agrupaba en dos partes: un primer semestre de principios básicos, transversal a los siete programas de grado, Arquitectura de interiores, Cine y televisión, Comunicación visual, Diseño industrial, Diseño textil y de moda, Interacción y medios digitales y Mercadotecnia y publicidad; y un segundo semestre dedicado a la relación del color con la superficie, el espacio, la percepción y la reproducción, impartido en todos los programas, excepto en Mercadotecnia y publicidad y Cine y televisión.

Esta modalidad de organización del contenido implicaba el aprendizaje de fundamentos teóricos mediante lecturas comentadas, revisión de materiales, realización de proyectos con mezcla de pigmentos y pintura manual. Estos ejercicios fueron discutidos en clase para establecer vínculos con las bases teóricas; las figuras 1, 2 y 3 ilustran los productos de este enfoque análogo.

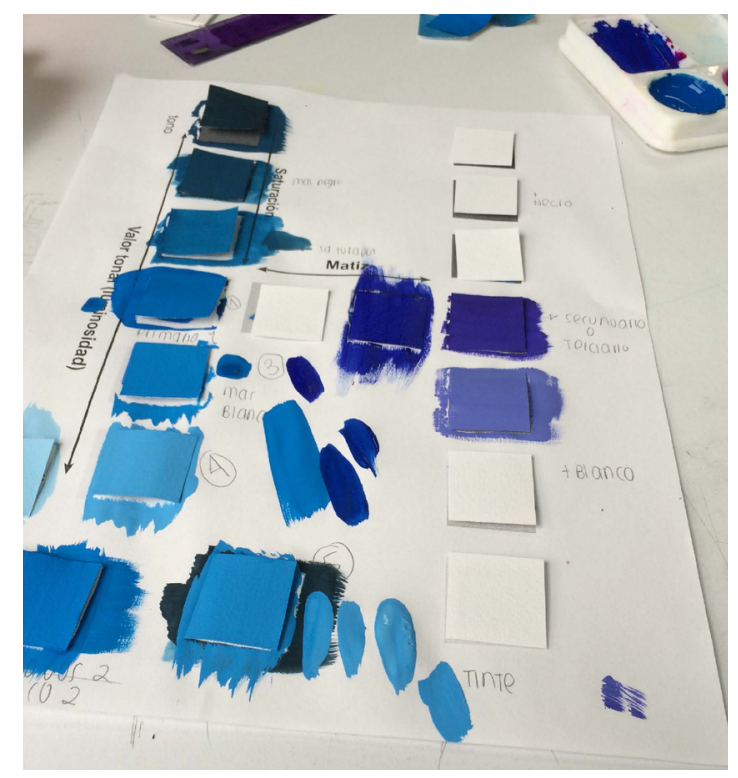

Figura 1. Alexa Fernández. Procesos. Ciudad de México:

Centro de diseño, cine y televisión. 2014. [Fotografía de archivo]. 

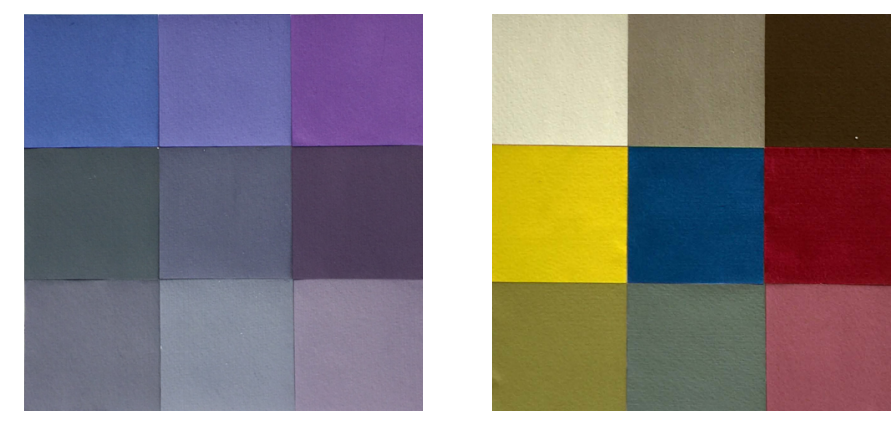

Figura 2 y 3. Guillermo Gómez. Grises Cromáticos.

Ciudad de México: Centro de diseño, cine y televisión. 2015.

[Imagen de archivo].

En el 2016, el programa académico de color fue modificado significativamente y en ese mismo año inició la transición hacia el nuevo modelo de enseñanza-aprendizaje. La modificación consistió en la fusión de los contenidos de ambos semestres en uno solo y en la traducción de la práctica otrora análoga al uso de la herramienta digital Processing, lenguaje de programación y entorno de desarrollo de código abierto dentro de un contexto de comunicación y artes visuales creado por Ben Fry y Casey Reas en 2001 (2016).

La adopción de este recurso no es azarosa. Las autoridades académicas de CENTRO lo consideraron óptimo por su flexibilidad, por ser de acceso libre y por su adopción exitosa alrededor del mundo en proyectos de educación, cultura e investigación; museos como el Exploratorium en San Francisco, California, han utilizado Processing para desarrollar sus exhibiciones; la Academia Kahn, también ha adoptado las innovaciones del aprendizaje a través de Processing para elaborar sus tutoriales en línea y numerosos proyectos creados con Processing han sido presentados en museos como el MoMA en Nueva York, el Centro Georges Pompidou en París o el Victoria and Albert en Londres.

Cabe aclarar que si bien el universo de herramientas de gestión, codificación, notación e igualación de color, como los sistemas Munsell, Natural Colour System, Pantone o RAL o los modelos Hostmann, Kast \& Schincke o Trumatch son internacionalmente utilizados en proyectos de comunicación visual, este estudio, así como la asignatura de color evaluada, únicamente aborda los conceptos desde los valores absolutos de las teorías aditiva y sustractiva -valores CMYK y RGB-, considerando que su adecuada comprensión es el primer paso para la asimilación de todos los demás sistemas y modelos. 
NUEVOS CÓDIGOS PARA LA ENSEÑANZA DEL COLOR.

ADOPTANDO EL LENGUAJE DEL PROCESSING

Para hacer posible la enseñanza de código mediante Processing, un grupo de seis profesores, cinco mujeres y un hombre, todos con mínimo dos años de experiencia en la impartición de la materia de color, recibieron una capacitación de dieciséis horas en el uso de la herramienta, factor que influyó de forma contundente en el proceso de enseñanza, ya que en cierto sentido tanto los profesores como los estudiantes arrancaron el curso siendo hablantes recién iniciados en el lenguaje que supone este recurso tecnológico. ${ }^{1}$

La observación cuyos resultados se exponen, se centra en tres grupos de estudiantes de licenciatura que fueron monitoreados de agosto a diciembre del 2016, con edades que oscilan entre los dieciocho y los veinte años, veintinueve mujeres y dieciséis hombres, trece de la licenciatura de Diseño textil, nueve de Cine y televisión, siete de Medios digitales, cuatro de Comunicación visual, cuatro de Diseño industrial y tres de Arquitectura de interiores. Los participantes tomaron un curso de habilidades básicas que incluyó los principios de Processing, que en la mayoría de los casos representó su primer acercamiento a la teoría del color y al aprendizaje mediante código.

Conviene aclarar que para efectos de este trabajo, entenderemos por código al "conjunto de instrucciones que componen un programa" (Glosario de informática e internet, 2015), mismas que traducen nuestros requerimientos al lenguaje de los diferentes dispositivos digitales.

Durante el periodo de observación, la materia se cursó tres horas por semana, lo cual supuso una adición a la carga regular de trabajo, que totalizó cuarenta y ocho horas presenciales más cuarenta y ocho horas de práctica individual extramuros.

¿Qué problemas se enfrentaron durante este proceso de adquisición de lenguaje? ¿Qué resultados se obtuvieron en esta primera experiencia? ¿Qué retos enfrenta la institución en materia de conversión de prácticas de enseñanza-aprendizaje con recursos digitales?

1 [Nota del Editor] Al cierre de esta edición el equipo docente cursa una segunda capacitación para refinar sus destrezas en el software. 
NUEVOS CÓDIGOS PARA LA ENSEÑANZA DEL COLOR.

ADOPTANDO EL LENGUAJE DEL PROCESSING

Son las preguntas que pretenden resolverse en este documento con el afán de dar seguimiento a una discusión necesaria que requiere de otras voces para nutrirse.

Autores como Wang, Westland, Cheung (2008) y Kooroshinia (2013) destacan la importancia del manejo del color (Color Management) y su física en el arte y el diseño. Han reunido evidencia del bajo nivel de conocimientos en esta materia por parte de los estudiantes universitarios que cursan el color como asignatura básica, mismos que —no obstante coinciden en el carácter crucial de la materia - en su gran mayoría son incapaces de identificar los colores primarios sustractivos; esto evidencia un fuerte contraste entre el discurso y la práctica en la enseñanza del color.

Por su parte, Kooroshinia (2013) señala la escasez de propuestas tendientes a facilitar la enseñanza de color con medios digitales, tema en el cual apunta a un rezago:

(...) los planteamientos ofrecen una visión profunda sobre cómo usar los colores en diferentes contextos y cómo combinar el color y los medios, pero no son adecuados para aplicarlos al aprendizaje y la enseñanza ... aún existe una falta de método de enseñanza que ayude a los estudiantes a llegar a una mejor comprensión de las transiciones de color (...) (Kooroshina 2013, 73) [Traducción por el editor] ${ }^{2}$

En El estudio del color de acuerdo con el pensamiento de diseño, Matilde Breña (2013) advierte sobre el abuso de los medios electrónicos, que puede incidir en la elaboración de proyectos limitados a las opciones precargadas en los programas, situación que:

(...) hace que se tienda a la homogenización y generalización; la imposición implícita da lugar a la ignorancia de particularidades que requieren sensibilidad

$2(\ldots)$ the approaches provides profound insight about how to use colors in different contexts, and how to match color and media but they are not adequate to apply to studying and of teaching... there is still a lack of teaching approach to help students arrive at a better understanding of the color transitions (...)(Kooroshina 2013, 73). 
NUEVOS CÓDIGOS PARA LA ENSEÑANZA DEL COLOR.

ADOPTANDO EL LENGUAJE DEL PROCESSING

y reflexión para compensar y adecuar una imagen a un concepto.

La instrucción de los diseñadores sólo a través del uso de computadoras

acaba siendo limitante, parcial y reduccionista (Breña, 2013, 57).

Por otra parte, Tan (2006) explora la sustitución de métodos tradicionales por nuevas tecnologías en el aula, tomando como parámetro la iniciativa del gobierno de Singapur para invertir en la industria de medios digitales, situación que repercute en la inclusión de tecnologías de ese orden en los procesos de enseñanza superior. A decir de la autora, la inclusión de herramientas digitales en la formación de grado para arte y diseño en etapas tempranas -específicamente en el primer año de un programa de tres-contribuye a la productividad y al interés por el aprendizaje, además de preparar a los estudiantes para el vertiginoso cambio que suponen las nuevas tecnologías.

La imagen digital es fácil de maniobrar, pero se limita en el repertorio de funciones que ofrece cada programa, lo cual deriva, entre otros resultados, en la semejanza de rasgos en los trabajos que los estudiantes elaboran; este hecho también es atribuible a los códigos culturales asociados con las representaciones visuales, en particular el color. Lo anterior no obsta para reconocer que, siguiendo a Breña (2013), la selección cromática a través de medios digitales se torna tan eficiente como automática, sin que se exija mayor vínculo o análisis por parte del proyectista.

La revisión de la literatura en materia de enseñanza del color arroja que los procesos manuales requieren de una planeación más sistemática en tanto no hay un comando para "deshacer", lo cual fortalece las habilidades analíticas, la observación, la concentración y conlleva también una aproximación distinta al error, que queda integrado al proceso creativo en lugar de revertirse. En consonancia con la visión de este estudio, que trasciende la dicotomía análogo-digital en busca de soluciones balanceadas, los estudios revisados coinciden en desaconsejar la total conversión de la enseñanza de color a procedimientos digitales, considerando la tecnología como un recurso que debiera facilitar la aprehensión de los procesos análogos, antes que reemplazarlos. 
NUEVOS CÓDIGOS PARA LA ENSEÑANZA DEL COLOR.

El día de hoy, los estudios del color y sus implicaciones han permitido el desarrollo de proyectos de toda índole y muchos han sido llevados a su proyección en tecnologías innovadoras y proyectos que repercuten en la manera que vemos y veremos el mundo, formando una parte activa en la economía creativa en la que los alumnos estarán inmersos en poco tiempo. Tal es el caso de Neil Harbisson, artista contemporáneo y activista cyborg británico e irlandés; Harbisson explica en Ted Talks (Listen to Color, 2012) que debido a un defecto congénito que le impide ver los colores (acromatopsia), es la primera persona en el mundo reconocida como cíborg por un gobierno y la primera persona con una antena implantada en la cabeza. La antena, co-creada por él mismo, le permite escuchar los colores y percibir colores invisibles como infrarrojos y ultravioletas, ya que esta tecnología traduce la frecuencia de los rayos electromagnéticos de la luz en vibraciones que van directo a su cóclea, logrando un sonido para cada rango de frecuencias y convirtiendo a Neil Harbisson en la primera persona capaz de escuchar los colores y ver la música (y los sonidos) de colores.

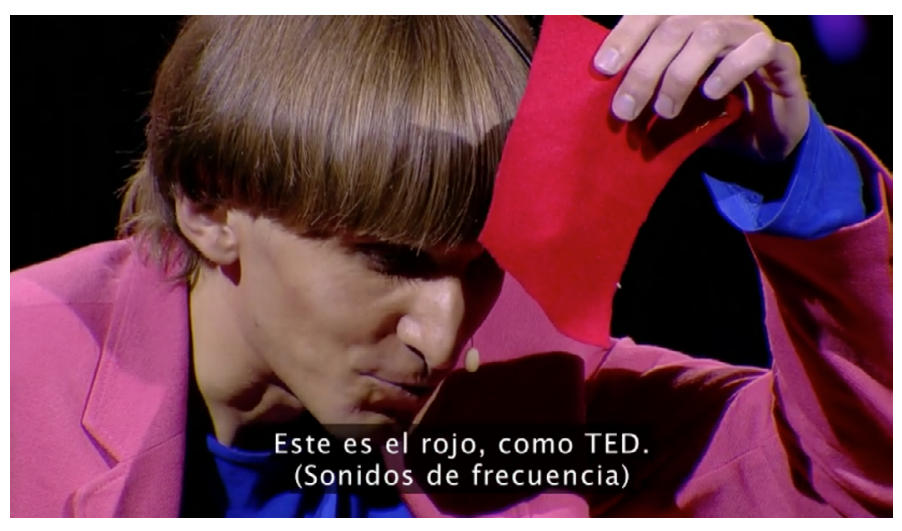

Figura 4. Neil Harbisson. (2012). Listen to Color. Ted Talks.

Los avances tecnológicos corren en paralelo con el comportamiento humano en sus diferentes dimensiones. La ciencia y el diseño como actividad creadora cada vez se acercan más. En la película The Matrix (Wachovsky, Andy \& Lana. 1999), los protagonistas son capaces de descifrar cascadas de códigos y traducirlas simultáneamente en imágenes en movimiento; este escenario que en su momento pareciera futurista, hoy es una realidad cotidiana para los profesionales de la informática y en breve lo será para los profesionales del diseño y el arte digital, solo para comenzar. 
Tal como ocurre en The Matrix, los alumnos que aprenden Processing deben traducir signos para ver en ellos algo más, en este caso colores, como se muestra en las figuras 5 y 6.

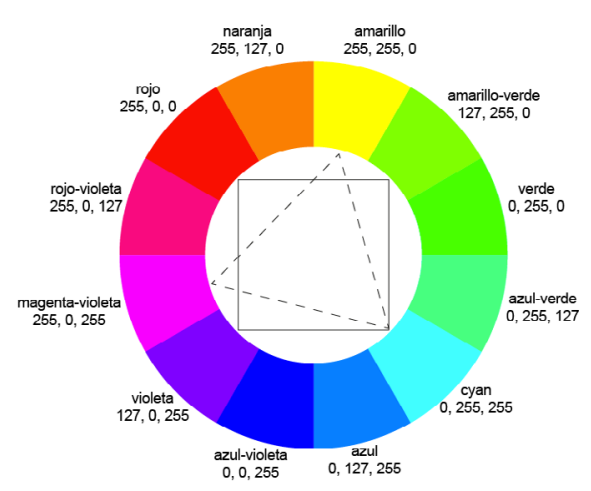

Figura 5. Fernanda Márquez. (2016).

Círculo cromático síntesis aditiva. [Material docente].

\begin{tabular}{|c|c|c|c|c|c|c|c|c|}
\hline C & M & Y & R & G & B & H & S & B \\
\hline 100 & - & - & - & 255 & 255 & $180^{\circ}$ & 100 & 100 \\
\hline- & 100 & - & 255 & - & 255 & $300^{\circ}$ & 100 & 100 \\
\hline- & - & 100 & 255 & 255 & - & $60^{\circ}$ & 100 & 100 \\
\hline- & 100 & 100 & 255 & - & - & & 100 & 100 \\
\hline 100 & - & 100 & - & 255 & - & $120^{\circ}$ & 100 & 100 \\
\hline 100 & 100 & - & - & - & 255 & $240^{\circ}$ & 100 & 100 \\
\hline- & 50 & 100 & 255 & 127 & - & $30^{\circ}$ & 100 & 100 \\
\hline 50 & - & 100 & 127 & 255 & - & $90^{\circ}$ & 100 & 100 \\
\hline 100 & - & 50 & - & 255 & 127 & $150^{\circ}$ & 100 & 100 \\
\hline- & 100 & 50 & 255 & - & 127 & $330^{\circ}$ & 100 & 100 \\
\hline 50 & 100 & & 127 & & 255 & $270^{\circ}$ & 100 & 100 \\
\hline 100 & 50 & - & - & 127 & 255 & $210^{\circ}$ & 100 & 100 \\
\hline
\end{tabular}

Figura 6. Fernanda Márquez. (2016). Tabla de equivalencias. [Material docente].

Los profesionales del diseño requieren, además del aprendizaje por medio de la manufactura, de una comprensión clara de los fundamentos científicos que deben sustentar sus proyectos y las herramientas tecnológicas con las que deberá crear la cara de un nuevo mundo. La experiencia en el aula debe ser congruente con esta tendencia.

Pero el estudio del color tiene tal coherencia con los fenómenos físicos, que una comprensión profunda y sólida de las bases de la teoría del color es suficiente para su adecuada aplicación en las nuevas tecnologías y para su adaptación a la evolución tecnológica y los cambios en los procesos de proyección, venta y consumo que el diseñador tendrá que enfrentar en su trayectoria profesional.

\section{Resultados}

El trabajo de campo para este estudio se desarrolló en cuatro etapas. La primera consistió en la elaboración de un diario de campo semestral (Apéndice 1) en el cual reseñé minuciosamente la observación y los procesos de aprendizaje del grupo de control. 
Extractos del diario de clase:

Sept 12, 2016

Hoy proyecté un ejercicio muy sencillo (básico) de Processing. Los alumnos

se asustaron. No hubo preguntas ni comentarios, lo cual me preocupa.

Les sorprendió que el matiz en HSB se midiera en grados y que el círculo cromático no era sólo una bonita manera de darle forma al arco iris.

Oct 4, 2016

Para comprender los conceptos de interacciones de color: duotonos, triadas y tétradas puse ejercicios sencillos para utilizar Processing combinados con ejercicios de recorte de color.

Los alumnos que llevaban computadora eligieron hacer primero la parte digital. Pudieron seguir las instrucciones y comenzaron a descubrir con sorpresa las relaciones matemáticas de los doce principales colores del círculo cromático (ver Apéndice 1).

En la segunda etapa se aplicaron cuestionarios pre y post test, para cuya interpretación se utilizó la taxonomía de Bloom como parámetro (Anderson et al. 2001). Posteriormente se aplicó el instrumento de evaluación desarrollado por Wang, Westland y Cheung (2008) (ver figura 7), cuyos reactivos consideran los siguientes aspectos:

Reactivo 1 | Importancia del color en el diseño (Irrelevante, no muy importante, a veces importante, muy importante y crítica)

Reactivo 2 | Reconocimiento de primarios aditivos

Reactivo 3 | Reconocimiento de primarios sustractivos

Reactivo 4 | Reconocimiento de color rojo en código

Reactivo 5 | Reconocimiento de color amarillo en código 
NUEVOS CÓDIGOS PARA LA ENSEÑANZA DEL COLOR.

ADOPTANDO EL LENGUAJE DEL PROCESSING

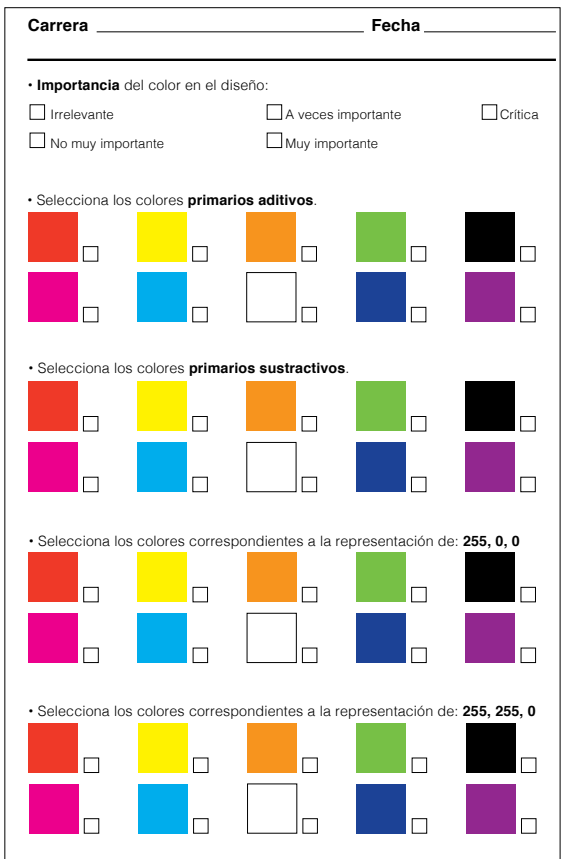

Figura 7. Evaluación: Wang, J., Westland, S., \& Cheung, V. (2008)

Durante el semestre los alumnos realizaron veinte ejercicios (ver Tabla 1) de los cuales cuatro fueron enteramente realizados en Processing. En el caso de los ejercicios realizados mezclando pigmentos cuyos objetivos no se cumplieron, los alumnos debieron reelaborar la pieza en Processing; lo mismo aplicó para las paletas de color del trabajo final. Las figuras $5,6,7,8$ y 9 ilustran algunos de estos ejercicios.

\section{Lista de ejercicios Objetivos}

\begin{tabular}{|l|l|l|}
\hline $\mathbf{1}$ Círculo cromático & $\begin{array}{l}\text { Encontrar y clasificar los colores del círculo } \\
\text { cromático en imágenes de revistas para } \\
\text { entrenar al ojo. }\end{array}$ & $\begin{array}{l}\text { Recorte de imágenes } \\
\text { de revistas. }\end{array}$ \\
\hline $\begin{array}{l}\mathbf{2} \text { Primarios, } \\
\text { secundarios } \\
\text { y terciarios }\end{array}$ & $\begin{array}{l}\text { Lograr los colores con la mezcla } \\
\text { de pigmentos. Agudizar la observación } \\
\text { y la precisión. }\end{array}$ & Mezcla de pigmentos. \\
\hline
\end{tabular}
Colour Knowledge in Design Education.

\section{Técnica}




\begin{tabular}{|c|c|c|}
\hline $\begin{array}{l}3 \text { Matiz y saturación } \\
\text { y valor tonal (cyan } \\
\text { a secundario) }\end{array}$ & \multirow{4}{*}{$\begin{array}{l}\text { Comprender estas tres propiedades } \\
\text { del color. }\end{array}$} & \multirow{6}{*}{ Mezcla de pigmentos. } \\
\hline $\begin{array}{l}4 \text { Matiz y saturación } \\
\text { y valor tonal (amarillo } \\
\text { a secundario) }\end{array}$ & & \\
\hline $\begin{array}{l}5 \text { Matiz y saturación } \\
\text { y valor tonal (magenta } \\
\text { a secundario) }\end{array}$ & & \\
\hline $\begin{array}{l}6 \text { Grises cromáticos } \\
\text { y acromáticos }\end{array}$ & & \\
\hline $\begin{array}{l}7 \text { Equivalencias } \\
\text { acromáticas }\end{array}$ & $\begin{array}{l}\text { Comprender conceptos de equivalencia } \\
\text { de luminosidad. }\end{array}$ & \\
\hline 8 Temperatura & $\begin{array}{l}\text { Aprender a identificar la temperatura } \\
\text { en imágenes y cambiarla aplicando } \\
\text { diferentes matices. }\end{array}$ & \\
\hline 9 Duotono análogo & \multirow{4}{*}{$\begin{array}{l}\text { Comprender interacciones y valores } \\
\text { complementarios. }\end{array}$} & \multirow{4}{*}{ Processing. } \\
\hline $\begin{array}{l}10 \text { Duotono } \\
\text { complementario }\end{array}$ & & \\
\hline $\begin{array}{l}11 \text { Triadas } \\
\text { equidistantes }\end{array}$ & & \\
\hline $\begin{array}{l}12 \text { Tétradas } \\
\text { equidistantes }\end{array}$ & & \\
\hline 13 Transparencias & $\begin{array}{l}\text { Comprender la diferencia entre tintes } \\
\text { y opacidades. }\end{array}$ & $\begin{array}{l}\text { Mezcla de pigmentos } \\
\text { y repeticiones } \\
\text { en Processing. }\end{array}$ \\
\hline 14 Tonos de piel & $\begin{array}{l}\text { Poner en práctica valores de matiz, } \\
\text { saturación y luminosidad. }\end{array}$ & $\begin{array}{l}\text { Mezcla de pigmentos } \\
\text { y equivalencies } \\
\text { en Processing. }\end{array}$ \\
\hline
\end{tabular}


NUEVOS CÓDIGOS PARA LA ENSEÑANZA DEL COLOR.

ADOPTANDO EL LENGUAJE DEL PROCESSING

\begin{tabular}{|c|c|c|}
\hline $\begin{array}{l}15 \text { Armonía } \\
\text { monocromática }\end{array}$ & \multirow{6}{*}{$\begin{array}{l}\text { Comprender y poner en práctica las } \\
\text { cualidades del color: armonías y contrastes. }\end{array}$} & \multirow{6}{*}{ Mezcla de pigmentos. } \\
\hline 16 Armonía de valor & & \\
\hline $\begin{array}{l}17 \text { Contraste } \\
\text { complementario }\end{array}$ & & \\
\hline $\begin{array}{l}18 \text { Contraste de } \\
\text { extensión }\end{array}$ & & \\
\hline $\begin{array}{l}19 \text { Contraste de } \\
\text { saturación }\end{array}$ & & \\
\hline $\begin{array}{l}20 \text { Armonía de valor } \\
\text { y contraste de matiz }\end{array}$ & & \\
\hline Trabajo final & $\begin{array}{l}\text { Poner en práctica todos los conceptos } \\
\text { aprendidos. }\end{array}$ & $\begin{array}{l}\text { Mezcla de pigmentos } \\
\text { y equivalencies } \\
\text { en Processing. } \\
\text { Análisis teórico. }\end{array}$ \\
\hline
\end{tabular}
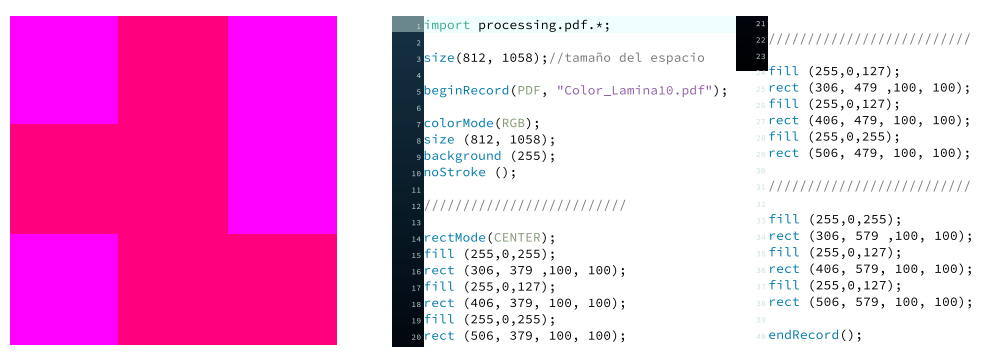

Figura 8. Duotono análogo. Marco Antonio Arauna. Duotono análogo en Processing. Ciudad de México: Centro de diseño, cine y televisión. 2016. [Imagen de archivo].
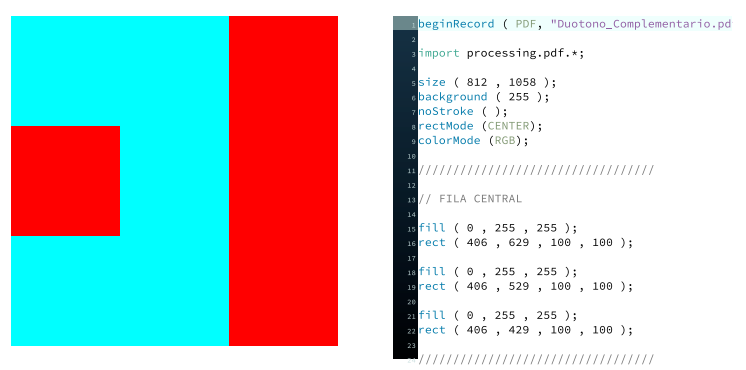

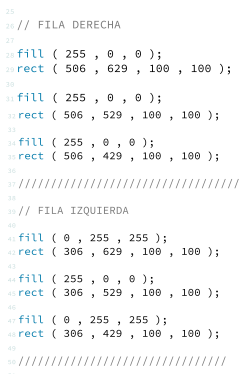

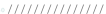

endrecord ();
Figura 9. Luis Ruiz. Duotono complementario en Processing. Ciudad de México: Centro de diseño, cine y televisión. 2016. [Imagen de archivo]. 
NUEVOS CÓDIGOS PARA LA ENSEÑANZA DEL COLOR.

ADOPTANDO EL LENGUAJE DEL PROCESSING
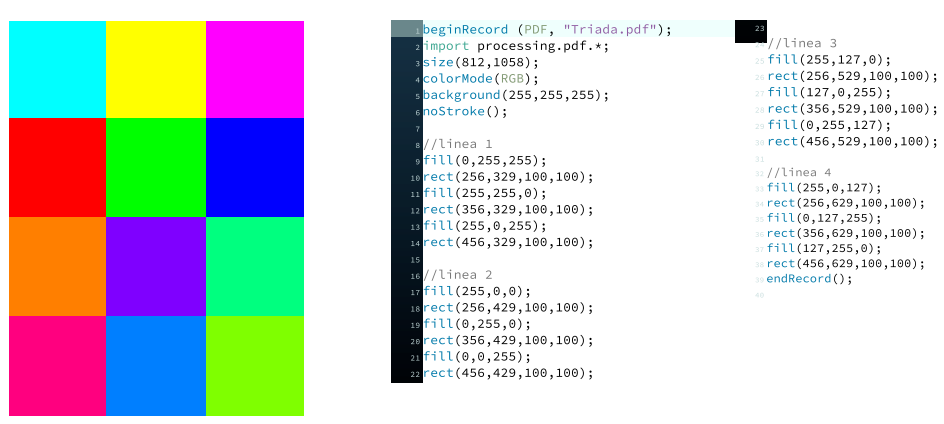

Figura 10. Isabel Madero. Triadas equidistantes en Processing Ciudad de México: Centro de diseño, cine y televisión. 2016. [Imagen de archivo].
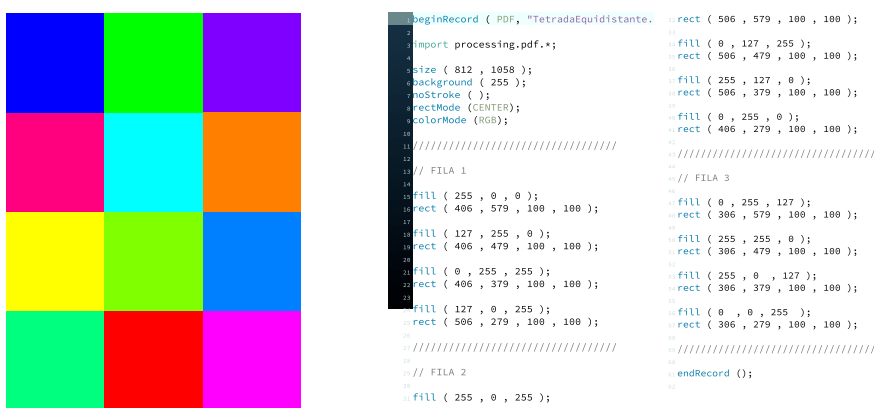

198, 190 );

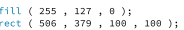

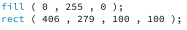

ffill $(8,255,127) ; ;$
$\operatorname{rect}(396,579,189,180)$;

fill $(255,255,8) ;$
rect $(306,479,108,109) ;$

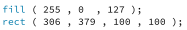

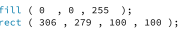

Figura 11. Mariana Abdo. Tétradas equidistantes. Ciudad de México: Centro de diseño, cine y televisión. 2014. [Imagen de archivo].
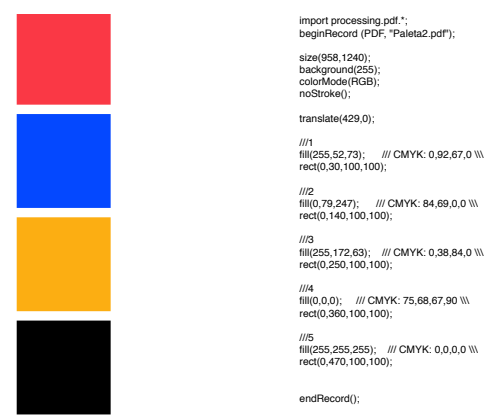

Figura 12. Luis Ruiz. Paleta de color en Processing RGB

con equivalencia CMYK. Ciudad de México: Centro de diseño, cine y televisión. 2016. [Imagen de archivo].

El primer cuestionario se aplicó en la sexta semana de clase, antes de comenzar los ejercicios con Processing. Previamente se les mostró el libro Generative Design (Bohnacker, Gross \& Laub, 2012). sobre posibles aplicaciones de esta herramienta y se enmarcaron las expectativas en función del plan de estudios de la materia. 
Las preguntas que los alumnos respondieron fueron las siguientes:

1 ¿Para qué sirve Processing? De manera general.

Ejemplos de respuestas:

- Para crear a través del diseño generativo y paramétrico.

- Para generar código aplicado a disciplinas de carácter visual.

- Crear figuras con precisión y rapidez (Extracto del Apéndice 2).

2 ¿Para qué te sirve a ti Processing? Vínculo del programa con sus expectativas personales. Ejemplos de respuestas:

- Crear animaciones, procesar imágenes, para identificarlas, crear juegos y aplicaciones.

- Hacer colores precisos y controlados.

- Utilizar nueva tecnología en los proyectos (Extracto del Apéndice 2).

Para identificar tendencias en los resultados de estas preguntas abiertas las respuestas se organizaron de acuerdo con la Taxonomía Bloom (en Anderson et al. 2001), tal como se indica en la tabla 2.

\begin{tabular}{|c|c|c|c|}
\hline \multicolumn{2}{|c|}{ ¿Para qué sirve Processing? } & \multicolumn{2}{|c|}{ ¿Para qué me sirve a mí Processing? } \\
\hline \multicolumn{4}{|c|}{ Coinciden } \\
\hline Verbo & Menciones & Verbo & Menciones \\
\hline Crear & 8 & Crear & 8 \\
\hline Diseñar & 8 & Diseñar & 8 \\
\hline Hacer | Realizar & 3 & Hacer | Realizar & 2 \\
\hline Formalizar (dar forma) & 2 & Formalizar (dar forma) & 1 \\
\hline \multicolumn{4}{|c|}{ No coinciden } \\
\hline Conocer & 1 & Representar & 1 \\
\hline Digitalizar & 3 & Identificar & 2 \\
\hline
\end{tabular}




\begin{tabular}{|l|l|l|l|}
\hline Generar & 1 & Utilizar & 1 \\
\hline Repetir & 1 & Aprender & 1 \\
\hline Dibujar & & Saber & 2 \\
\hline Programar & 2 & Reproducir & 1 \\
\hline Producir & 1 & Cursar & 2 \\
\hline Ayudar & 1 & Entender & 1 \\
\hline Combinar & 1 & Observar & 1 \\
\hline \multirow{2}{*}{} & & Facilitar & 1 \\
\cline { 3 - 4 } & & Conocer & 1 \\
\cline { 2 - 4 } & & Obtener & 1 \\
\cline { 2 - 4 } & & Controlar & 1 \\
\cline { 2 - 4 } & & &
\end{tabular}

La mayoría de las respuestas para ambas preguntas utilizan verbos como "crear" y "diseñar", lo que, según Bloom (en Anderson et al. 2001) ubica la expectativa de utilización del software en el orden más alto y complejo de habilidades cognitivas. El verbo "crear" se encuentra en la dimensión metacognitiva del conocimiento. En segundo lugar se ubica el verbo "hacer/realizar", también en la dimensión metacognitiva del conocimiento, pero en los procesos cognitivos de "aplicación".

Se identificaron confluencias entre las dos preguntas en cuatro verbos: crear, diseñar, hacer/ realizar y formalizar. La respuesta fue mucho más precisa cuando se planteó de manera impersonal, mientras que al preguntar para qué le sirve Processing al alumno, las respuestas se dispersaron en diez y siete verbos distintos. Es decir, se observó un contraste importante entre la expectativa a nivel global y el potencial práctico que el participante contempla para su persona. 
NUEVOS CÓDIGOS PARA LA ENSEÑANZA DEL COLOR.

Al terminar los cuatro primeros ejercicios realizados con Processing, los alumnos elaboraron un texto breve narrando su experiencia con esta nueva herramienta. Los participantes coincidieron en que con esta herramienta se obtienen resultados precisos y limpios más rápidamente. La mayoría se expresaron positivamente con respecto a este recurso, también se manifestó una inquietud por la carencia de una preparación previa, ya que la comprensión del funcionamiento del programa les tomó mucho tiempo.

Algunas respuestas del cuestionario 2 (Apéndice 3 - Cuestionario 2)

\section{Alumno de Mercadotecnia y publicidad}

En general, creo que no fue una tarea complicada, aunque sí me tomó tiempo realizarla debido a que aún no es una herramienta muy dominada. Lo que más tiempo me costó fue encontrar los valores.

\section{Alumno de Diseño textil y moda}

Me gusta más cómo se ve en Processing porque siento que todo se veía más limpio y es más rápido.

\section{Alumno de Arquitectura de interiores}

Me gustó más trabajar en Processing que a mano, porque es más fácil obtener los colores correctos, no tienes que pegar ni recortar y la impresión queda más limpia.

La prueba de Wang, Westland y Cheung se aplicó en la doceava semana de clases, cuatro semanas antes de terminar el semestre, con los resultados que se indican en la tabla 3:

\begin{tabular}{|l|l|l|l|l|l|l|l|}
\hline Carrera & $\begin{array}{l}\text { A veces } \\
\text { importante }\end{array}$ & $\begin{array}{l}\text { Muy } \\
\text { importante }\end{array}$ & Crítico & $\mathbf{1}$ & $\mathbf{2}$ & $\mathbf{3}$ & $\mathbf{4}$ \\
\hline Diseño Textil y Moda & & 9 & 4 & 8 & 9 & 9 & 4 \\
\hline Cine y Televisión & 1 & 1 & 1 & 0 & 2 & 2 & 1 \\
\hline
\end{tabular}


NUEVOS CÓDIGOS PARA LA ENSEÑANZA DEL COLOR.

ADOPTANDO EL LENGUAJE DEL PROCESSING

\begin{tabular}{|c|c|c|c|c|c|c|c|}
\hline Diseño Industrial & & 2 & 3 & 4 & 4 & 3 & 2 \\
\hline Mercadotecnia y Publicidad & & 3 & 1 & 2 & 3 & 4 & 1 \\
\hline Arquitectura de Interiores & & 3 & 1 & 3 & 3 & 2 & 1 \\
\hline Comunicación Visual & 1 & 6 & 4 & 7 & 9 & 9 & 5 \\
\hline $\begin{array}{l}\text { Interacción } \\
\text { y Medios Digitales }\end{array}$ & & 5 & & 4 & 3 & 4 & 4 \\
\hline \multirow[t]{2}{*}{ Total: 45 personas } & 2 & 29 & 14 & 28 & 33 & 33 & 18 \\
\hline & $4.4 \%$ & $64.4 \%$ & $31.1 \%$ & $62.2 \%$ & $73.3 \%$ & $73.3 \%$ & $40 \%$ \\
\hline
\end{tabular}

Tabla 3. Resultados de aplicación de evaluación.

Pregunta 1: Relevancia

Irrelevante

No muy importante

A veces importante

Muy importante

Crítico

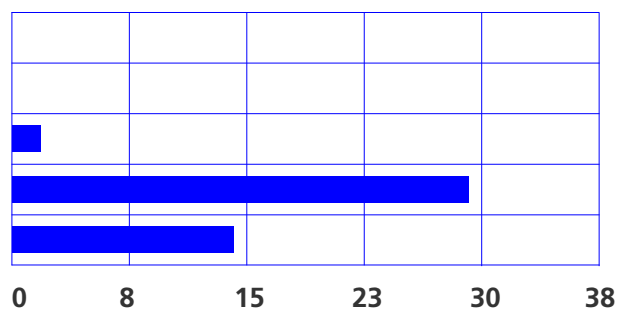

Tabla 4. Tabla 4: Resultado de aplicación de evaluación. Pregunta 1.

Pregunta 2: primarios - aditiva

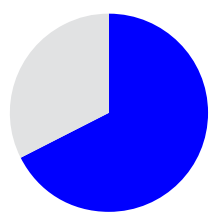

Identificación correcta de primarios síntesis aditiva No identificó

Pregunta 4: 255,0,0

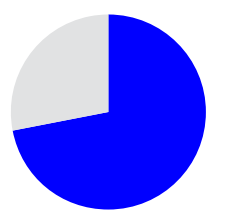

Identificación correcta de 255,0,0 No identificó
Pregunta 3: primarios - sustractiva

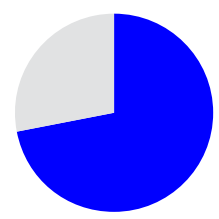

Identificación correcta de primarios síntesis sustractiva No identificó

Pregunta 5: 255,255,0

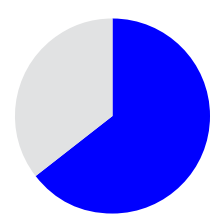

Identificación correcta de 255,255,0 No identificó
Tabla 5. Resultado de aplicación de evaluación. Preguntas 2, 3, 4 y 5 
NUEVOS CÓDIGOS PARA LA ENSEÑANZA DEL COLOR.

ADOPTANDO EL LENGUAJE DEL PROCESSING

Como se indica en la figura 5, la evaluación muestra que el $64.4 \%$ de los alumnos considera "muy importante" el estudio del color en su desarrollo profesional y $31 \%$ lo consideran "crítico". Sumando ambas cifras podemos decir que la mayoría (95.4\%) está consciente del valor que le da el conocimiento de la teoría del color al estudio y desarrollo de sus disciplinas.

A través de la enseñanza con Processing se muestra una mejor comprensión de la síntesis aditiva, ya que $73.3 \%$ de los alumnos pudo identificar correctamente los colores primarios, en comparación con el $62.2 \%$ que identificó correctamente los primarios sustractivos, a pesar de haber enseñado éstos con procesos manuales y ejercicios ya conocidos y evaluados por los profesores en semestres anteriores.

Una vez que se conocen los primarios aditivos, la deducción del color rojo es relativamente sencilla, esto explica el $73.3 \%$ de asertividad en la prueba, en contraste con el $40 \%$ de alumnos que pudieron identificar el secundario aditivo, siendo que su deducción lógica menos clara.

\section{Discusión}

Durante la implementación de Processing se detectó que los alumnos no tenían los conocimientos básicos para el manejo del programa, lo cual demoró la implementación de los ejercicios y requirió de la inversión de tiempo en asesorías, en detrimento del tiempo requerido para la compresión de otros contenidos relacionados con la teoría del color. Esta situación se agravó debido a que el equipo docente a cargo del curso también se encontraba en una etapa de aprehensión inicial de la herramienta y sus alcances.

En una fase inicial, hubo rechazo por parte de algunos alumnos, pero una vez que pudieron realizar óptimamente los ejercicios, notaron que los resultados eran más precisos y limpios, hubo una creciente predilección por utilizarlo, sobre todo por parte de aquellos alumnos menos diestros en actividades manuales. 
No todos los estudiantes tienen la misma disposición al aprendizaje a través de medios, así como no todos tienen las mismas destrezas para pintar. Los estudiantes de Medios digitales comprenden rápidamente el funcionamiento de Processing y fungen como mentores de sus demás compañeros, lo cual indica una aceptación diferenciada según la carrera; las disciplinas que requieren más habilidades manuales -Comunicación visual, Diseño industrial y Diseño textil y moda- son las que, en un principio rechazan la utilización del programa, mientras que los alumnos de Medios digitales son los que mejor aceptan los ejercicios con el programa, siendo que la mayoría está familiarizada con los lenguajes en código desde antes de comenzar la enseñanza universitaria.

En conclusión, se muestra una buena comprensión de la síntesis aditiva y las cifras de identificación de los primarios y secundarios, de la síntesis sustractiva son optimistas, aunque aún no existe un estudio comparativo dentro de CENTRO, lo cual constituye una asignatura pendiente.

Se demostró la necesidad de la creación de herramientas docentes que ayuden a la comprensión de las bases teóricas del color para su aplicación digital, así como de métodos de evaluación y comprobación de la autoría de los ejercicios.

Los profesores enfrentamos el reto de adquirir y perfeccionar el uso de este y otros recursos tecnológicos para facilitar nuestro trabajo docente. Lo mismo en el caso del color que de otras asignaturas clave para el proceso creativo. 


\section{Referencias}

Anderson, L.W. (Ed.); Krathwohl, D.R. (Ed.); Airasian, P.W.; Cruikshank, K.A.; Mayer, R.E., Pintrich; P.R., Raths, J. \& Wittrock, M.C. (2001). A taxonomy for learning, teaching, and assessing: A revision of Bloom's Taxonomy of Educational Objetives. New York: Longman.

Antico, Concetta. (2016). Beyond Average Color Vision. Recuperado de: http://munsell.com/color-blog/ tetrachromat-artist-concetta-antico/

Beneyto, Raúl G. (2015). ¿Cuánta información se genera y almacena en el mundo?. Recuperado de: https:// documania20.wordpress.com/2015/09/16/cuantainformacion-se-genera-y-almacena-en-el-mundo/

Bohnacker, Hartmut; Gross, Benedikt \& Laub, Julia. (2012). Generative Design: Visualize, Program, and Create with Processing. Princeton Architectural Press, E.U.A.

Breña, María Angélica Matilde. (2013). El estudio del color de acuerdo con el pensamiento de diseño. UNAM, México.

Centro de Diseño, Cine y Television. (2015). Reglamento CENTRO. Ciudad de México.

Cisco. (2015). Internet será cuatro veces más grande. Recuperado de: http://www.cisco.com/web/ES/about/ press/2015/2015-05-30-internet-sera-cuatro-vecesmas-grande/

\section{Apéndices}

Apéndice 1 | Diario de clase (Fernanda Márquez 2016)

Apéndice 2 | Cuestionario 1. ¿Para qué sirve el Processing?, ¿para qué me sirve a mi?.

(Fernanda Márquez 2016)
Glosario de informática e internet (2015). Recuperado de: http://www.internetglosario.com/letra-c.html

Harbisson, Neil. (2012). Listen to Color. TED Talks. Recuperado de: https://www.ted.com/talks/neil_ harbisson_i_listen to_color

Kooroshinia, Marjan. (2013). Demostrating Color Transitions of Leuco Dye-Based Thermochromic inks as a teaching approach in textile and fashion design. The Swedish School of Textiles, University of Boras, Boras, Sweden. Recuperado de: http://www.nordes. org/opj/index.php/n13/article/download/289/271

Processing. (2015). Welcome to Processing. Recuperado de: https://processing.org/Cover

Sharma, Abhay. (2004). Understanding color management. ppVii. Thomson Delmar Learning. E.U.A.

Siong-Hoon, Wendy Tan. (2006). Can Teaching Colour Digitally Completely Replace Teaching Colour Tradicionally?. Singapore. Recuperado de http://files. eric.ed.gov/fulltext/ED491959.pdf

Wachovsky, Lana \& Lilly. (1999). The Matrix. E.U.A. / Australia.

Wang, J.; Westland, S., \& Cheung, V. (2008). Colour Knowledge in Design Education. School of Design, University of Leeds, UK.
Apéndice 3 | Cuestionario 2. Describe tu experiencia al trabajar con Processing. (Fernanda Márquez 2016) 